\title{
Risk assessment of electricity price regulation for power grid enterprises based on system dynamics model
}

\author{
Huiru Zhao ${ }^{1}$, Sitong Liu ${ }^{1}$, Bingkang Li $^{1}$, Peipei You ${ }^{2}$, Rengcun Fang ${ }^{3}$ and Sen Guo ${ }^{1, *}$ \\ ${ }^{1}$ School of Economics and Management, North China Electric Power University, Beijing 102206, China \\ 2 Department of Finance, Accounting and Auditing Research, State Grid Energy Research Institute, Beijing 102209, China \\ ${ }^{3}$ Economic and Technology Research Institute of State Grid Hubei Electric Power Company, Hubei province 430077, China
}

\begin{abstract}
The new round of power system reform has strengthened the supervision of transmission and distribution links, and changed the profit model of power grid enterprises by verifying the transmission and distribution price. In this context, the research on the regulatory risk faced by power grid enterprises under the electricity price regulatory policy can provide tools and decision support for power grid enterprises to accurately grasp the regulatory risk and reduce the risk loss. Firstly, combined with the transmission and distribution price supervision process faced by power grid enterprises, the possible risks faced by power grid enterprises in price supervision are analyzed. Secondly, the quantitative measurement model of electricity price regulation of power grid enterprises is constructed by using system dynamics, and the effectiveness of the model is verified. Finally, the future regulatory period is simulated and the results are analyzed, and policy recommendations are put forward.
\end{abstract}

\section{Introduction}

China's transmission and distribution (T\&D) electricity price reform has gradually moved towards strong supervision. The government's supervision on power grid enterprises is increasingly focused on the T\&D electricity price. He, et al pointed out that China is carrying out a new round of power system reform, controlling the income of power grid enterprises through the T\&D tariff policy [1]. Wang, et al pointed out that the reform of T\&D fee limits the income of China's grid companies and increases the operating pressure[2]. Liu, et al analysed the investment decision of power grid under the reform of transmission and distribution electricity price, proposed the estimation model of power grid investment demand and the measurement model of power grid enterprise investment capacity, and constructed the optimization model of power grid investment scale[3].

System dynamics (SD) analyzes the structure and function of the whole system. It can also observe the changes of the whole system by changing the parameters in the system, so as to find the best way to solve the system problems. SD is suitable to take complex system as the research object, and has good applicability for the study of complex system problems. Relevant scholars also introduce SD into the field of risk measurement, Liu, et al constructed the SD model of gas pipeline risk assessment considering failure probability and accident consequence[4]. Ali, et al used SD method to study the possibility and impact of environmental and operational risk from four dimensions: variable cost, fixed cost, quality performance and revenue[5]. Wang, et al established the financial capability model of power grid company by using system dynamics theory[6].

The pricing process and execution process of $T \& D$ price regulation is also a complex system, so the regulatory risk faced by power enterprises can also be applied to the system dynamics model.

\section{Regulatory risk analysis of power grid enterprises}

The whole process of T\&D price supervision faced by power grid enterprises mainly includes four links: pricing, price implementation, operation and constraints.

Pricing is the starting point of transmission and distribution price supervision, usually at the beginning of the supervision period. The main regulatory matters involved in the pricing process include the total scale, reasonable income, allowable cost and price level of the effective assets of power grid enterprises during the period of supervision and approval. The implementation of electricity price starts after the pricing phase, and runs through the whole supervision cycle. The grid enterprises will determine the actual implementation price in the supervision period based on the price level approved at the beginning of the period, and then determine the actual implementation price in the supervision period in combination with the national policy price adjustment requirements.

The operation is mainly the process of normal production and operation activities of power grid enterprises under the approved price level. During the supervision period, the actual operation may be inconsistent with the electricity, cost and profit at the

*Corresponding author: guosen@ncepu.edu.cn 
beginning of the period. The regulatory authorities will stipulate the corresponding allowable scope for these inconsistencies. If they exceed the specified allowable range, grid enterprises will face corresponding constraints when the price is checked in the next regulatory cycle. The constraint is a process that comprehensively considers the difference between the actual operating level of power grid enterprises in the supervision cycle and the set value of the initial price in the supervision period, and then influences the grid enterprises in the next supervision cycle. The main way to restrict the grid enterprises is to influence the approval of grid investment, allowable cost and permitted return rate in the next regulatory cycle, and to influence the approval of allowable cost in the next supervision cycle.

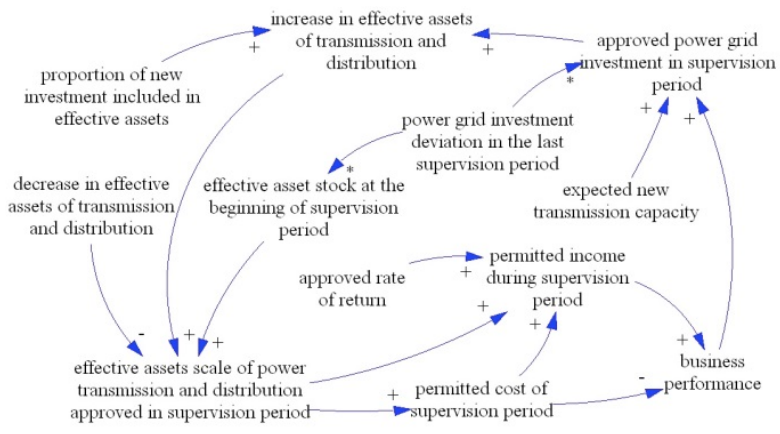

(a)

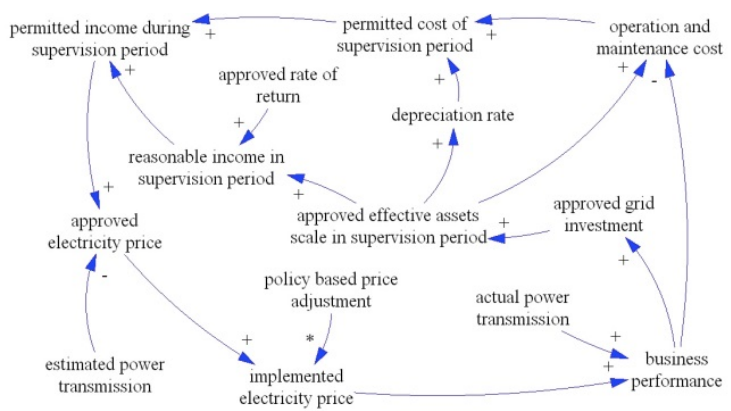

(c)

\section{Measurement model of electricity price regulation risk for power grid enterprises}

The quantitative measurement model of electricity price supervision risk of power grid enterprises based on system dynamics mainly includes four subsystems: transmission and distribution effective assets subsystem, transmission and distribution permitted cost subsystem, electricity price approval subsystem and operation effect subsystem.

The indicators that characterize the operation performance of power grid enterprises mainly include total profit, economic value added, effective asset profit rate, operating income profit rate, $R \& D$ investment intensity, annual 10000-yuan asset operation and maintenance cost, debt service coverage rate, interest coverage rate, etc. Then, the causality diagram of the four subsystems is drawn as shown in figure 1.

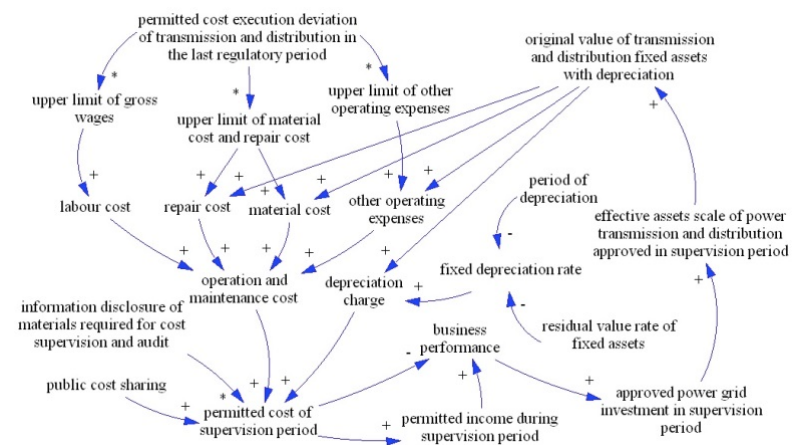

(b)

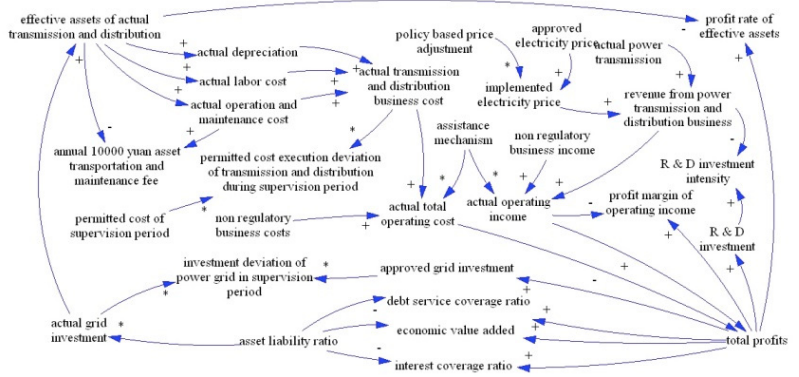

(d)

Figure 1. Cause and effect diagram of subsystem.

The main factors that affect the scale of effective assets of power transmission and distribution during the supervision period are: the scale of power grid investment, effective assets verification rules, expected new power transmission, and the operation performance of power grid enterprises. The main influencing factors of the permitted cost in the supervision period are: the implementation of the permitted cost of power transmission and distribution in the last supervision period, the supervision and examination rules of the cost of power transmission and distribution, the approved investment scale of power grid, and the operation effect of power grid enterprises. The main influencing factors of the approved electricity price in the supervision period are: effective assets approval rules, transmission and distribution cost supervision rules, estimated power transmission, operation performance of power grid enterprises, etc. The main factors affecting the operation effectiveness of power grid enterprises are: the actual income of power transmission and distribution business, the actual cost of power transmission and distribution business, non-regulatory business income and support mechanism, effective assets of power transmission and distribution, asset liability ratio, etc.

There are many feedback loops including "operation effect" in the effective assets subsystem, the permitted cost subsystem and the electricity price approval subsystem of transmission and distribution, and these 
feedback loops are also applicable to the operation effect subsystem.

Combined with the relationship between the indicators, the equation of state in the model is as follows:

$$
\begin{gathered}
A_{\mathrm{Ap}}=\operatorname{INTEG}\left(R A_{i, \mathrm{Ap}}-R A_{o, \mathrm{Ap}}, A_{\mathrm{Ap}, 0}\right) \\
A_{\mathrm{Ac}}=\operatorname{INTEG}\left(R A_{i, \mathrm{Ac}}-R A_{o, \mathrm{Ac}}, A_{\mathrm{Ac}, 0}\right) \\
D e p=\operatorname{INTEG}\left(R D e p, D e p_{0}\right) \\
R \& D=\operatorname{INTEG}\left(R R \& D, R \& D_{0}\right) \\
D e b=\operatorname{INTEG}\left(\text { Deb }_{i}-\text { Deb }_{o}, D_{e} b_{0}\right)
\end{gathered}
$$

where $A_{\mathrm{Ap}}$ is the effective assets of transmission and distribution in the supervision period, $R A_{i, \mathrm{Ap}}$ is the new effective assets of transmission and distribution in the supervision period, $R A_{o, \mathrm{Ap}}$ is the reduced effective assets of transmission and distribution in the supervision period, and $A_{\mathrm{Ap}, 0}$ is the stock of effective assets of transmission and distribution at the end of the previous supervision period, which is the initial value of effective assets of transmission and distribution at the beginning of this supervision period. $A_{\mathrm{Ac}}$ is the effective assets of actual transmission and distribution, $R A_{i, \mathrm{Ac}}$ is the effective assets of actual new transmission and distribution, $R A_{o, \mathrm{Ac}}$ is the effective assets of actual verification and reduction of transmission and distribution, and $A_{\mathrm{Ac}, 0}$ is the stock of effective assets of transmission and distribution at the end of last supervision period, which is the initial value of effective assets of transmission and distribution at the beginning of this supervision period. Dep is the depreciation amount accrued in the supervision period, $R D e p$ is the annual depreciation amount accrued in the supervision period, and $D e p_{0}$ is the initial value of $D e p . R \& D$ is the cumulative $R \& D$ investment, $R R \& D$ is the annual $R \& D$ investment in the regulatory period, and $R \& D_{0}$ is the initial value of $R \& D$. $D e b$ is the debt balance, $D e b_{i}$ is the new loan in the supervision period, $D e b_{o}$ is the annual principal and interest repayment in the supervision period, and $D e b_{0}$ is the initial value of $D e b$.

The rate equation in the model is as follows:

$$
\begin{gathered}
R A_{i, \mathrm{Ap}}=P o G I_{\mathrm{Ap}} \times R_{\mathrm{PoGI}} \\
R A_{i, \mathrm{Ac}}=P o G I_{\mathrm{Ac}} \times R_{\mathrm{PoGI}} \\
R D e p=A_{\mathrm{Ap}} \times R_{\mathrm{Dep}} \\
R R \& D=P r o f \times R_{R \& \mathrm{D}} \\
D e b_{o}=D e b \times R_{D e b}+D e b / N_{D e b}
\end{gathered}
$$

where $P o G I_{\mathrm{Ap}}$ is the approved grid investment, $R_{\text {PoGI }}$ is the proportion of new investment included in effective assets, $P O G I_{\mathrm{Ac}}$ is the actual grid investment, $R_{\mathrm{Dep}}$ is the pricing depreciation rate, Prof is the total profit, $R_{R \& D}$ is the proportion of $\mathrm{R} \& \mathrm{D}$ investment, $R_{D e b}$ is the loan interest rate, and $N_{D e b}$ is the repayment period.

\section{Case Study}

In this study, a provincial power grid company in China is taken as an example to verify and analyse the model. The model aims to explore the regulatory risks faced by power grid enterprises under the regulatory policy of transmission and distribution price.

\subsection{Parameter determination}

The model is expected to run for 9 years (2017-2025) with an interval of 3 years (one regulatory cycle). Constant value setting: the proportion of new investment included in effective assets is $70 \%$, the residual value rate is $5 \%$, the depreciation period is 30 years, the return on equity capital is $8 \%$, the return on debt capital is $6 \%$, the income tax rate is $25 \%$, the value-added tax rate is $17 \%$, the urban maintenance and construction tax rate is $7 \%$, the education surcharge rate is $3 \%$, the loan interest rate is $6 \%$, the repayment period is 15 years, and the average capital cost rate is $6 \%$. For the first supervision period (2017-2019), some initial parameters are set as follows: labour rate is $0.32 \%$, material rate is $0.33 \%$, repair rate is $0.34 \%$, other operation rate is $0.05 \%$, and asset liability ratio is $65 \%$. In addition, the completion of information disclosure is initially set as complete, and the allowable input tax deduction and assistance mechanism are initially set as 0 .

\subsection{Empirical analysis and results}

According to the basic information of the example, the system dynamics is used to simulate the model, and finally the income, cost and profit, $R \& D$ investment, asset operation and maintenance investment and profitability are used as the index to judge the risk of electricity price regulation, as shown in figure 2.

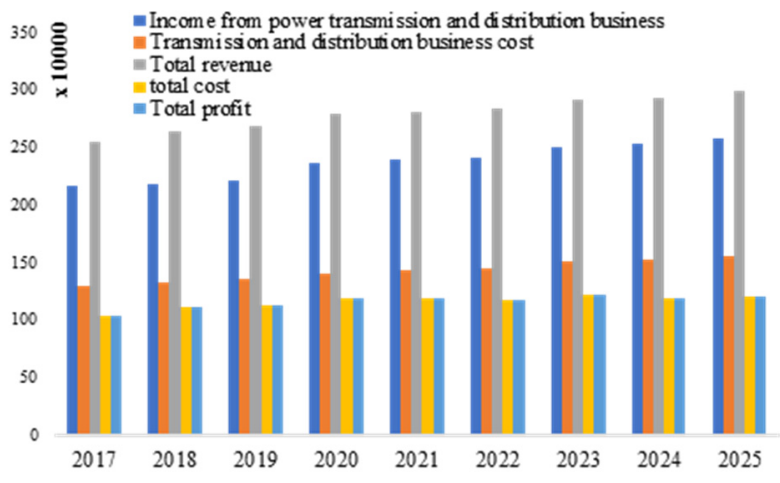

(a) 


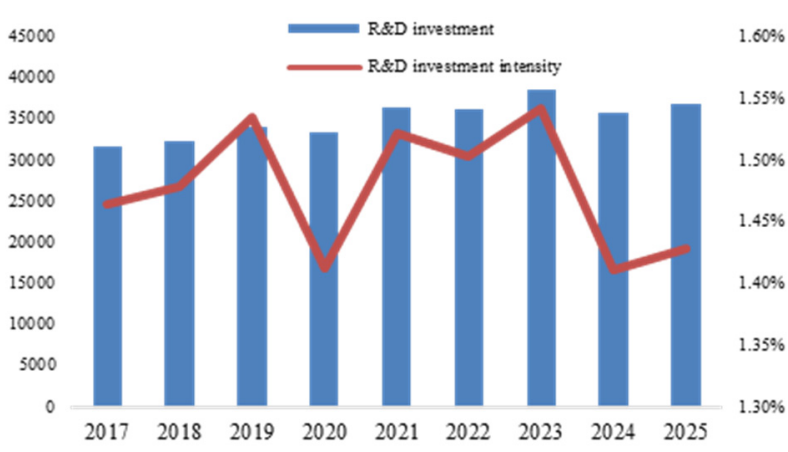

(b)

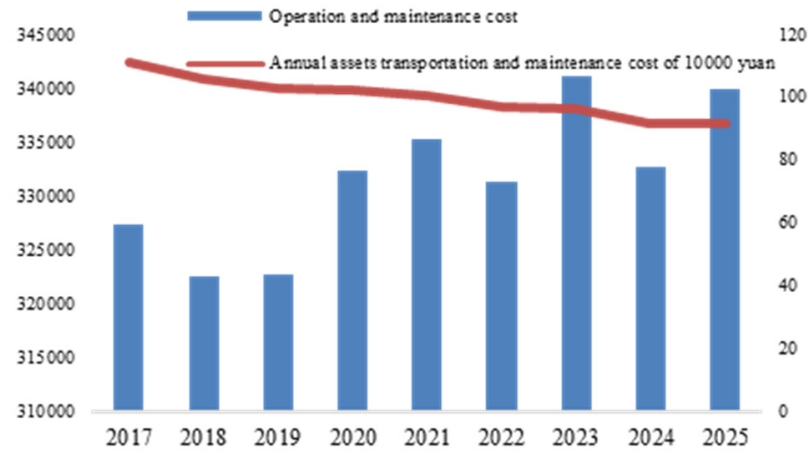

(c)

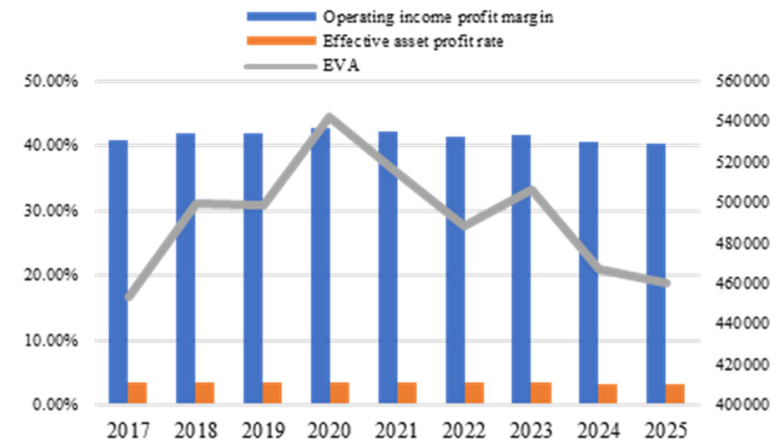

(d)

Figure 2. Model simulation results.

It can be seen that the business income and total income of power grid enterprises increase steadily year by year, while the business cost and total cost of power grid enterprises also increase. The total profit of the company is relatively stable, which indicates that under the influence of electricity price regulation policy, the company has no significant risk of profit fluctuation. There are some fluctuations in R\&D investment of power grid enterprises in each supervision period, but the volatility is small. The company's R\&D investment intensity is relatively stable. There are some fluctuations in the operation and maintenance fees of power grid enterprises in each supervision period, but the volatility is small. The company's annual asset operation and maintenance fee of 10000 yuan is decreasing year by year. The economic added value of power grid enterprises fluctuates in each supervision period. The profit margin of effective assets of the company is relatively stable; the profit margin of operating income is slightly higher than $40 \%$ and relatively stable. The simulation results show that the profitability of the company is stable under the influence of the electricity price regulation policy, that is, the electricity price regulation policy will not have a severe impact on the profitability of the company.

\section{Conclusion}

This paper constructs a system dynamics model to reflect the risk of electricity price supervision of power grid enterprises, and makes an empirical analysis of a provincial power grid enterprise in China, and forecasts the next supervision cycle. The results show that although the electricity price regulation policy will have an impact on the power grid companies, it is only a small fluctuation and will not cause a huge impact, that is, the operation of power grid companies under the condition of load regulation policy will not cause too much risk. With the strict regional regulatory policy of transmission and distribution pricing, power grid companies need to complete their due responsibilities from their own point of view, such as cost control and information disclosure. The risk quantification model constructed in this study can also help power grid companies to reasonably avoid risks and provide reference tools.

\section{Acknowledgments}

This research was funded by the project "Theory, technology and application on regulatory risk management and information disclosure of power grid enterprises under electricity transmission and distribution tariff reform" of the Science and Technology Project of the State Grid Corporation of China (1400201957285A-0-0-00).

\section{References}

1. Y. He, J. Jiao, R. Chen, Energy Policy, 113, 112122 (2018)

2. Y. Wang, M. Zhou, F. Zhang, Energy, 219, 119589 (2021)

3. D. Liu, E. Xu, G. Qin, Energy Procedia, 156, 412416 (2019)

4. A. Liu, K. Chen, X. Huang, Reliab. Eng. Syst. Saf., 208, 107326 (2021)

5. M. Ali, A. Melek, V. Uday, Logistics, 4, 34 (2020)

6. Y. Wang, F. Zhang, Y. Zhang, Util. Policy, 60, 100941 (2019) 